Article

\title{
Engineering Functionalized Chitosan-Based Sorbent Material: Characterization and Sorption of Toxic Elements
}

\author{
Adnan Khan ${ }^{1,2, *}$, Nisar Ali ${ }^{3}$, Muhammad Bilal ${ }^{4}$, Sumeet Malik ${ }^{2}$, Syed Badshah ${ }^{5}$ and \\ Hafiz M. N. Iqbal ${ }^{6, *(D)}$
}

1 Institute of Chemistry, University of Campinas, UNICAMP, P.O. Box 6154, Campinas 13084-971, SP, Brazil

2 Institute of Chemical Sciences, University of Peshawar, Khyber Pakhtunkhwa 25120, Pakistan; sumeetmalik1995@gmail.com

3 Key Laboratory for Palygorskite Science and Applied Technology of Jiangsu Province, National \& Local Joint Engineering Research Center for Deep Utilization Technology of Rock-salt Resource, Faculty of Chemical Engineering, Huaiyin Institute of Technology, Huaian 223003, China; nisarali@hyit.edu.cn

4 School of Life Science and Food Engineering, Huaiyin Institute of Technology, Huaian 223003, China; bilaluaf@hotmail.com

5 Department of Chemsitry, Gomal University, D. I. Khan 29220, Pakistan; syedbadshah_hej@yahoo.com

6 School of Engineering and Sciences, Campus Monterrey, Tecnologico de Monterrey,

Ave Eugenio Garza Sada 2501, Monterrey CP 64849, N.L., Mexico

* Correspondence: adnankhan@uop.edu.pk (A.K.); hafiz.iqbal@tec.mx (H.M.N.I.); Tel.: +52-81-8358-2000 (ext. 5679) (H.M.N.I.)

Received: 28 October 2019; Accepted: 23 November 2019; Published: 27 November 2019

\begin{abstract}
The present study reports the engineering of functionalized chitosan $(\mathrm{CH})$-based biosorbent material. Herein, a two-step reaction was performed to chemically modify the $\mathrm{CH}$ using 1,4-bis(3-aminopropyl) piperazine to incorporate nitrogen basic centers for cations sorption from the aqueous environment. The resultant functionalized chitosan-based sorbent material was designated as $\mathrm{CH}$-ANP and characterized using various analytical techniques, including elemental analysis, Fourier-transform infrared spectroscopy (FTIR), ${ }^{13} \mathrm{C}$ NMR (in solid-state), X-ray diffraction, and thermal analysis. Then, the newly engineered $\mathrm{CH}$-ANP was employed for the removal of copper, lead, and cadmium in the aqueous medium. Langmuir sorption isotherm analysis revealed that the highest sorption abilities achieved were $2.82,1.96$, and $1.60 \mathrm{mmol} \mathrm{g}^{-1}$ for copper, cadmium, and lead, respectively. Linear and nonlinear regression methods were deployed on the sorption data to study the behavior of the Langmuir, the Freundlich, and the Temkin sorption isotherms. Among the four different forms, the Langmuir isotherm type 1 fit well to the experimental data as compared to the other models. It also showed the lowest values of error, and a higher correlation coefficient than the Freundlich and Temkin models; thus it was the best fit with the experimental data compared to the latter two models. In conclusion, the findings suggest that chemically modified novel materials with enhanced Lewis basic centers are useful and promising candidates for the sorption of various toxic cations in aqueous solution.
\end{abstract}

Keywords: sorption; chitosan; functionalization; glycidyl methacrylate; characterization; cation removal; isotherm

\section{Introduction}

The release of toxic metal cations to the ecosystem through industrial wastewater is an alarming situation. The presence of such metal ions is a threat to animals and humans due to its toxic nature 
in both soil and water [1]. These metals ions entered the aquatic environment through wastewater coming from different industries such as the fertilizer industry, mining, ore, refining, electroplating, painting, batteries, and tanneries [2]. One of the most toxic metal ions is lead, which is considered as a natural toxin. Lead is mostly released from factories, metal recycling, lead-acid batteries, and pipes [3]. Its exposure can cause reproductive, renal, hematopoietic, and central nervous system disorders in the human body [4]. Acute exposure mostly results in headaches, nausea, emotional disruption, and cognitive changes [5]. Cadmium, a heavy metal ion, has an ample noxiousness and harmful impact on most of the organ systems [6]. Cadmium is considered as one of the toxic substances to humans and can cause death. Exposure to cadmium through soil, water, and air can cause cancer, respiratory, central, and peripheral nervous, urinary, and skeletal disorders [7]. Copper is a crucial component for human body, acting as a cofactor of a variety of enzymes such as cytochrome oxidase, ceruloplasmin, superoxide dismutase, dopamine $\beta$-hydroxylase, and tyrosinase. However, excess copper and other toxic metal ions can disturb the capability of the liver for disrupting excess copper contents inside the human body. Thus, eventually affecting the organ system such as nervous, reproductive, and adrenal functions, connective tissues, the learning ability of newborn babies, etc. [8-11].

Various physical and chemical processes have been developed for the decontamination of these toxic metal ions from industrial effluents such as filtration [12], solvent extraction [13], precipitation, ion exchanger [14], reverse osmosis [15], oxidation/reduction [16], filtration [12], electrochemical techniques [17], and sorption [18,19]. Currently, sorption is advocated as one the most efficient, low-cost, and simple techniques for eliminating toxic metal ions from aqueous solution. It is currently perceived as a successful and monetary strategy for the expulsion of contaminants from water and wastewater systems. Therefore, there is a need for synthesizing an efficient, low cost, simple, and environmentally friendly sorbent for cations remediation from wastewater [20]. For the decontamination of these toxic metal ions from wastewater, a variety of synthetic as well as natural polymers is being manufactured or modified chemically. Sorbents obtained from biopolymers of natural origin have immensely being used to remove heavy metal ions from industrial wastewater and related aqueous environments [21]. Biopolymers can completely decontaminate metal ions from industrial effluents. The class of said biopolymers subsumes cellulose, chitin, chitosan, lignins, alginate, and carrageens [22-24].

After cellulose, chitin is considered the most abundant natural polymer obtained from the arthropod's exoskeleton, mostly crabs (Malacostraca) and insects (Insecta) [25]. Chitosan is a linear polysaccharide and deacetylated derivative of chitin [24]. It has been intensively applied in food industries, biomedical, biotechnological, pharmaceutical, cosmetics, agricultural, and water treatment [26]. Chitosan is biocompatible, environmentally friendly, antibacterial, and biodegradable; it also demonstrates high sorption capacity toward metal ions because of the chemical composition of amino and hydroxyl groups [24,27]. The degree of deacetylation is the main controlling factor for sorption capacity [28]; it also affects the properties of chitosan, which are mainly physical, chemical, and biological. The alteration of natural polymers is an effective technique for the manufacturing of new materials to present extraordinary properties and amplify the field of the plausible uses of those large existing biopolymers [29]. Different strategies have been utilized either to change characteristic chitosan physically or artificially to boost up the sorption limit [30]. In earlier studies, it has been confirmed that the available functional amino hydroxyl entities at the second and sixth carbon locations empower an assortment of chemical alterations [31]. Chitosan $(\mathrm{CH})$ has been alluring on the grounds that the available functional entities impart the cationic and chelating characteristics, which are useful for its functionalization and/or to engineer functionalized $\mathrm{CH}$-based constructs. The chemically altered $\mathrm{CH}$ has a more prominent take-up limit with respect to substantial metal ions [32].

The presented investigation was objected to chemically modify chitosan with glycidyl methacrylate [23], followed by reaction with 1,4-bis(3-aminopropyl) piperazine in a second step to increase the number of Lewis basic centers for decontamination from aqueous solution. The aim of the work is to prepare a green sorbent with a high sorption capacity for cations. The biodegradability and nontoxicity of the chitosan and modified products make them sustainable tools for wastewater 
treatment. After characterization, the as-prepared material was subjected to investigate its sorption capacity for copper, cadmium, and lead metal ions in aqueous solutions. The chemically modified chitosan's sorption limit was additionally assessed by contemplating the equilibrium sorption isotherm for copper, cadmium, and lead with a batch-wise procedure. The sorption capacity of the newly engineered material was compared with the raw chitosan. Moreover, to get the equilibrium information, several sorption isotherms, i.e., (1) the Langmuir, (2) the Freundlich, and the (3) Temkin and parameter values of these isotherms were also acquired in this study.

\section{Materials and Methods}

\subsection{Chemicals, Reagents and Materials}

Chitosan (78\% of deacetylation, Mwt $195 \mathrm{kDa})$ powder was obtained from the Primex Ingredients A.S. (Norway). Ethanol (Synth), 1,4-bis (3-aminopropyl)piperazine (Sigma-Aldrich, St. Louis, MO, USA), copper, cadmium, and lead nitrates all were of analytical quality and were used without further treatment.

\subsection{Procedure for Modification of Chitosan}

The present study involves a two-step reaction to modify the $\mathrm{CH}$ for cations sorption from aqueous environment. Firstly, $\mathrm{CH}$ modification was performed using glycidyl methacrylate by the reaction of its epoxy ring with the amino group of chitosan, which leads to the opening of the three-member ring through nucleophilic substitution reaction. In neutral $\mathrm{pH}$, the amino group of chitosan is most favorable nucleophilic center. The reaction was reported for the first time using environmentally friendly solvent water [22]. In the second step, this product, which contains a double bond of the glycidyl methacrylate, acts as Michael's acceptor in a reaction with 1,4-bis (3-aminopropyl) piperazine using triethylamine as a catalyst. In a typical procedure, $\mathrm{CH}(4.0 \mathrm{~g})$ was taken in 250-mL three-necked flasks containing $200 \mathrm{~mL}$ of water. The suspension was continuously shaken for $15 \mathrm{~min}$ at $353 \mathrm{~K}$. After getting a homogenous mixture, $2.65 \mathrm{~mL}$ of glycidyl methacrylate was slowly incorporated and placed under constant stirring for $2 \mathrm{~h}$. The resultant material ( $\mathrm{CH}$-gly) was filtered, repeatedly washed with ethanol, and dried under a vacuumed environment for $6 \mathrm{~h}$ at $318 \mathrm{~K}$. In the second phase, $3.0 \mathrm{~g}$ of $\mathrm{CH}$-gly was added to $150 \mathrm{~mL}$ of ethanol in a three-necked flask of $250 \mathrm{~mL}$ under constant stirring at $333 \mathrm{~K}$. Then, $3.0 \mathrm{~mL}$ of 1,4-bis (3-aminopropyl) piperazine was added, followed by the addition of $1.0 \mathrm{~mL}$ of catalyst, namely triethylamine $\left(\mathrm{Et}_{3} \mathrm{~N}\right)$. For completion of the reaction, the above mixture was mechanically stirred for up to $72 \mathrm{~h}$. After the designated reaction time, the chemically modified chitosan (CH-APN) was filtered and ethanol washed, which was followed by deionized water washing, and then dried under a vacuumed environment for $6 \mathrm{~h}$ at $318 \mathrm{~K}$. The schematic illustration of the whole chemical reaction is shown in Figure 1. 
Step 1
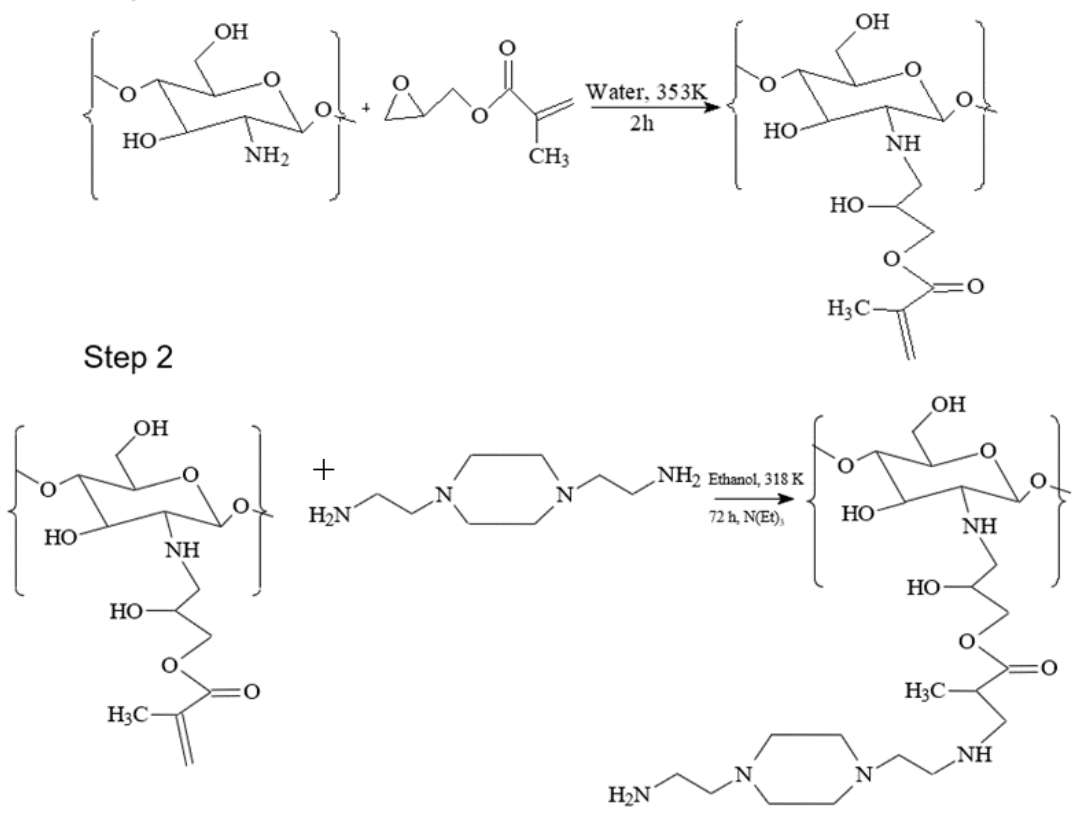

Figure 1. A stepwise illustration of the chemical reaction performed to modify the chitosan $(\mathrm{CH})$. Step 1 involves the reaction between $\mathrm{CH}$ and glycidyl methacrylate, while step 2 shows the reaction between $\mathrm{CH}$ modified in step 1 and 1,4-bis (3-aminopropyl) piperazine. At the end of this two-step reaction, the requisite products of modified chitosan, i.e., $\mathrm{CH}$-gly (from step 1) and chemically modified chitosan (CH-ANP, from step 2) were obtained.

\subsection{Characterization Studies}

The elemental analysis of pristine and modified $\mathrm{CH}$ material was carried out using a Perkin Elmer model PE 2400 elemental analyzer. Fourier-transform infrared spectroscopy (FTIR) was performed using a Bomem Spectrophotometer (MB-series). All test samples, i.e., pristine $\mathrm{CH}$, and the requisite products of modified chitosan, i.e., $\mathrm{CH}$-gly and $\mathrm{CH}$-ANP were prepared as $\mathrm{KBr}$ pellets. Then, the test samples containing $\mathrm{KBr}$ pellets were used to record the FT-IR spectra at the wavelength range, i.e., $4000-400 \mathrm{~cm}^{-1}$ with 32 scans and $4 \mathrm{~cm}^{-1}$ resolution.

The solid-state ${ }^{13} \mathrm{C}$ NMR spectra of the samples, i.e., pristine $\mathrm{CH}, \mathrm{CH}$-gly, and $\mathrm{CH}-\mathrm{ANP}$ materials was performed using a Bruker AC 300/P spectrometer. The evaluations were recorded at $75.47-\mathrm{MHz}$ frequencies, along with 4-kHz magic angle spinning, 5-s pulse repetitions, and a 1-ms time of contact. Shimadzu XD-3A diffractometer ( $35 \mathrm{kv}, 25 \mathrm{~mA}$ ) was utilized for X-ray diffraction patterns, in $2 \theta$ form between the range of $1.5^{\circ}$ and $50^{\circ}$ with nickel-filtered $\mathrm{CuK} \alpha$ radiation, and 0.154-nm wavelength. A Shimadzu TGA 50 apparatus was used for thermogravimetric curves, argon-filled air at a $1.67 \mathrm{~cm}^{3} \mathrm{~s}^{-1}$ flow rate, with a $0.167 \mathrm{~K} \mathrm{~s}^{-1}$ heat rate. The cation sorption extent was persuaded by figuring out the diversity between the initial concentration in the aqueous solution and that of the supernatant.

\subsection{Sorption Experiments}

The batch process was used to investigate the metal ions sorption ability of the modified chitosan from aqueous solution. In a typical procedure, $25.0 \mathrm{~mL}$ of metal solution was taken in a different polyethylene flask, and $20 \mathrm{mg}$ of the newly prepared material was added to it. The concentration of the metal solution used in the experiment ranged from $7.0 \times 10^{-4}$ to $2.0 \times 10^{-3} \mathrm{~mol} \mathrm{dm}^{-3}$ at neutral $\mathrm{pH}$. In order to obtain the period associated with the saturation of the isotherms, kinetic experiments were previously performed using similar cationic solutions. The suspension was shaken by an orbital apparatus at $298 \pm 1 \mathrm{~K}$ for $24 \mathrm{~h}$ to reach isothermal saturation. This time was previously established by using the same procedure to obtain an isotherm with a well-defined plateau, indicating that all basic centers in each biopolymer were saturated by cations. An isotherm having a well-defined plateau was 
obtained by a similar method after $4 \mathrm{~h}$ of contact time, demonstrating the saturation of basic centers on chitosan. The number of cations sorbed was determined by separating the supernatant solution from the solid material through decantation. The aliquot obtained was analyzed using ICP-OES (Inductively coupled plasma-optical emission spectrometry) for the presence of cations, and the quantity of the cations sorbed in the sorption process was calculated $\left(\mathrm{mmol} \mathrm{g}^{-1}\right)$ by Equation (1).

$$
N f=\frac{n i-n s}{m}
$$

where $N f, n i$, and $n s$ represent the number of mole of cations at the equilibrium stage, while $m$ represents the mass of the sorbent [33]. In addition, during the whole sorption process, the linear and nonlinear methods were applied to study the Langmuir, the Freundlich, and the Temkin isothermal behavior.

\section{Results and Discussion}

The chemical modification of $\mathrm{CH}$ was performed in two-step reactions to obtain the requisite products of modified $\mathrm{CH}$, i.e., $\mathrm{CH}$-ANP. It was expected that the newly engineered material based on modified $\mathrm{CH}$, i.e., $\mathrm{CH}$-ANP, could have a higher affinity toward cations from the aqueous solution than its pristine $\mathrm{CH}$ counterpart.

\subsection{Elemental Analysis}

Elemental analysis confirmed the chemical modification of $\mathrm{CH}$ by expressing a change in the percentage of nitrogen and carbon along with their correspondent $\mathrm{C} / \mathrm{N}$ molar ratio. The results obtained are summarized in Table 1 . The change in the amount of these elements $\left(L_{0}\right)$ was determined using Equation (2) [22,34]. When chitosan was treated with glycidyl methacrylate in the first step, the amount of carbon increased, and the nitrogen decreased from 7.39 to $5.89 \mathrm{mmol} \mathrm{g}^{-1}$, whereas the $\mathrm{C} / \mathrm{N}$ ratio increased from 6.42 to $8.73 \mathrm{mmol} \mathrm{g}^{-1}$ due to the absence of nitrogen inside the glycidyl methacrylate molecule. On the other hand, the quantity of nitrogen increased, and the $\mathrm{C} / \mathrm{N}$ ratio dropped to $7.31 \mathrm{mmol} \mathrm{g}^{-1}$ when this material was reacted with 1,4-bis(3-aminopropyl) piperazine. It is speculated that the increase in the amount of nitrogen will provide excessive basic centers for cations. These results show the incorporation of 1,4-bis(3-aminopropyl) piperazine molecule in the chitosan backbone. Hence, it will result in a higher sorption of cations from aqueous solution.

$$
L_{0}=\frac{\% \text { Element } \times 10}{\text { Atomic mass of element }}
$$

Table 1. Elemental analysis profile showing the available carbon $(\mathrm{C})$, and nitrogen $(\mathrm{N})$ in percent, number of moles, and the corresponding $\mathrm{C} / \mathrm{N}$ molar ratio of pristine $\mathrm{CH}$ and modified $\mathrm{CH}$ materials, i.e., $\mathrm{CH}$-gly and $\mathrm{CH}$-ANP.

\begin{tabular}{cccccc}
\hline Sample & $\mathbf{C} / \%$ & $\mathbf{N} / \%$ & $\mathbf{C} / \mathbf{m m o l ~ g}^{\mathbf{1}}$ & $\mathbf{N} / \mathbf{m m o l ~ g}^{-\mathbf{1}}$ & $\mathbf{C} / \mathbf{N}$ \\
\hline $\mathrm{CH}$ & 40.63 & 7.39 & 33.86 & 5.27 & 6.42 \\
\hline CH-gly & 44.04 & 5.89 & 36.7 & 4.20 & 8.73 \\
\hline CH-ANP & 45.65 & 5.38 & 38.04 & 5.20 & 7.31 \\
\hline
\end{tabular}

\subsection{Fourier-Transform Infrared Spectroscopy (FTIR)}

The FTIR spectra were recorded to study the change in the functional entities in the $\mathrm{CH}$ modified materials, i.e., $\mathrm{CH}$-gly and $\mathrm{CH}$-ANP. The chemical modification of $\mathrm{CH}$ with 1,4-bis (3-aminopropyl) piperazine (CH-ANP) was further substantiated by comparing its FTIR spectrum with $\mathrm{CH}$ and $\mathrm{CH}$-gly. A typical FTIR spectrum of chitosan showed characteristic bands at (i) $3405 \mathrm{~cm}^{-1}$ because of the $\mathrm{OH}$ and $\mathrm{NH}_{2}$ stretching vibrations, while the (ii) bands at 2916 and $2877 \mathrm{~cm}^{-1}$ were due to the $\mathrm{C}-\mathrm{H}$ 
stretching vibrations. (iii) Amide 1 showed a band at $1655 \mathrm{~cm}^{-1}$, while (iv) the band for the $\mathrm{N}-\mathrm{H}$ bond and primary $\mathrm{OH}$ alcohol bond appeared at $1592 \mathrm{~cm}^{-1}$ and $1426 \mathrm{~cm}^{-1}$, respectively. (vi) The $\mathrm{CH}_{3}$ symmetrical deformation mode appeared at 1379 and $1419 \mathrm{~cm}^{-1}$. (vii) The band for the $\mathrm{C}-\mathrm{O}$ stretching vibration and $\beta$-glycosidic bond between carbon 1 and 4 was presented at $1076 \mathrm{~cm}^{-1}$. The spectra of chemically modified chitosan $\mathrm{CH}$-gly and $\mathrm{CH}$-ANP were different from the pristine chitosan, as can be seen in Figure 2. The $\mathrm{CH}$-gly showed a band at $1719 \mathrm{~cm}^{-1}$ that represents the carbonyl of glycidyl methacrylate and a stretching vibration carbon double bond at $1635 \mathrm{~cm}^{-1}$. In the second step of the modification, the reaction of $\mathrm{CH}$-gly with 1,4-bis (3-aminopropyl)piperazine results in the disappearance of the double bond in the spectrum of $\mathrm{CH}$-ANP, which corroborates the successful attachement of 1,4-bis (3-aminopropyl)piperazine to CH-gly [34].

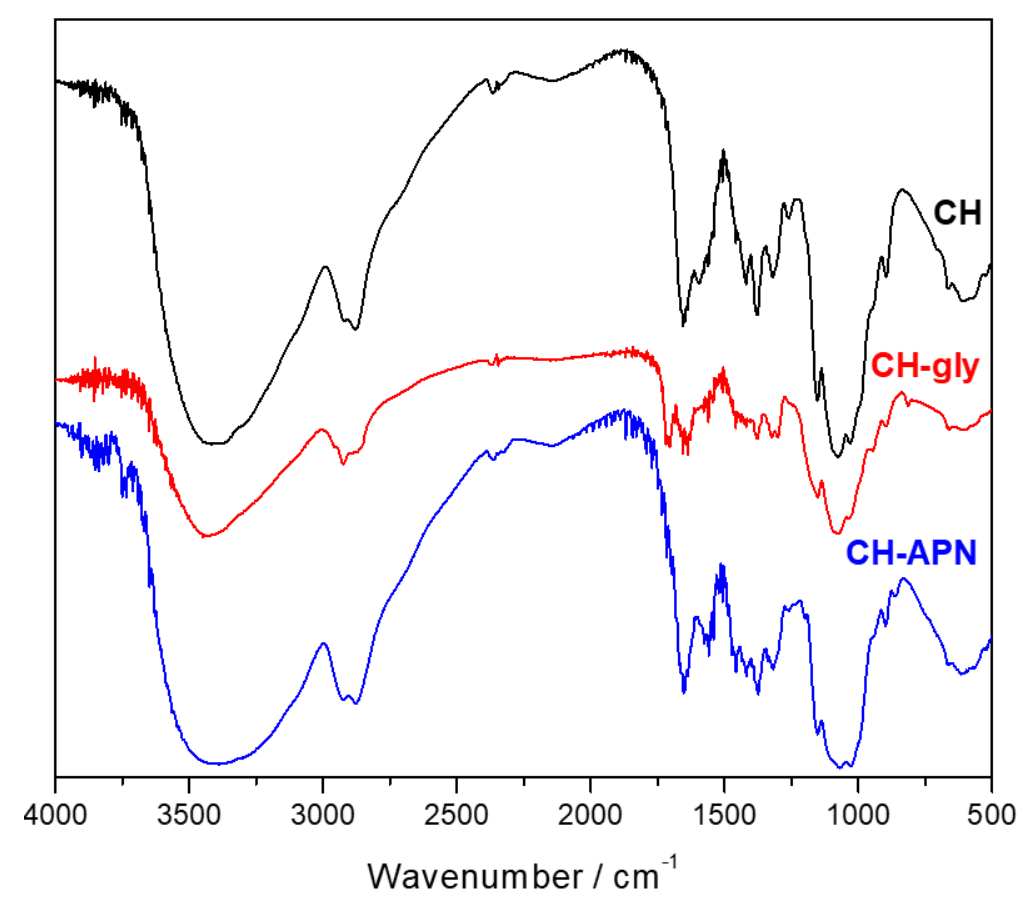

Figure 2. Fourier-transform infrared spectroscopy (FTIR) spectra of pristine $\mathrm{CH}$ and chemically modified $\mathrm{CH}$-based materials, i.e., $\mathrm{CH}$-gly and $\mathrm{CH}$-ANP.

\subsection{The ${ }^{13}$ C NMR Spectral Analysis}

The presence of new basic centers was shown by the nuclear magnetic resonance spectrum of the $\mathrm{CH}-\mathrm{ANP}$. The spectrum of chitosan showed a characteristic peak for $\mathrm{C} 1$ at $105 \mathrm{ppm}$. The peaks for $C 2$ and $C_{3} / C_{5}$ appeared at $58 \mathrm{ppm}$ and $75 \mathrm{ppm}$, respectively. The $\mathrm{C}_{4}$ and $\mathrm{C}_{6}$ showed peaks at 84 ppm and 62 ppm, respectively, as indicated in Figure 3. Both peaks at 175 ppm and 19 ppm are due to the presence of carbonyl carbon and the methyl group of chitin due to incomplete deacetylation. The chemically modified chitosan $\mathrm{CH}$-gly indicated two prominent peaks at $128 \mathrm{ppm}$ and $137 \mathrm{ppm}$, which were due to the double bond of glycidyl methacrylate [22]. Other peaks at $19 \mathrm{ppm}$ and 169 ppm are associated with methyl and carbonyl of glycidyl methacrylate, confirming the first step of the modification of chitosan. However, when this intermediate product was further altered (CH-ANP) in the second step, the two peaks at $128 \mathrm{ppm}$ and $137 \mathrm{ppm}$ due to vinyl carbon disappeared, showing the attachment of 1,4-bis (3-aminopropyl)piperazine molecule to this product. This also supports our results from elemental and FTIR spectroscopy in increasing the Lewis basic centers for cations sorption from aqueous medium. 


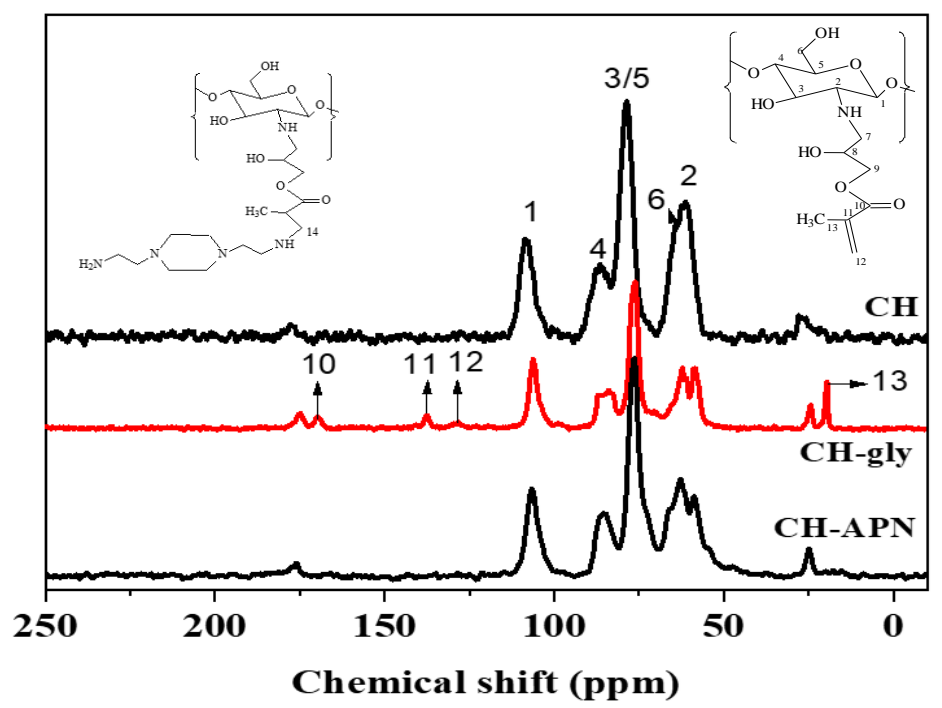

Figure 3. Chemical shift profile based on the ${ }^{13} \mathrm{C}$ NMR spectra of pristine $\mathrm{CH}$ and chemically modified $\mathrm{CH}$-based materials, i.e., $\mathrm{CH}$-gly and $\mathrm{CH}$-ANP.

\subsection{Thermal Analysis of $\mathrm{CH}-\mathrm{Gly}$ and $\mathrm{CH}-\mathrm{ANP}$}

Figures 4 and 5 both show the thermal behavior of pristine $\mathrm{CH}$ and the chemically modified final product, i.e., CH-ANP, respectively. Differential curves for both the materials clearly showed two distinctive peaks for chitosan and CH-ANP, respectively. As shown in Figure 4, the DTG (Derivative thermogravimetric curve) of $\mathrm{CH}$ showed a mass loss of $9 \%$ due to water at $335 \mathrm{~K}$, and the other peak appeared at $570 \mathrm{~K}$ with $57 \%$ mass loss. The modified $\mathrm{CH}$ indicated a characteristic peak at $328 \mathrm{~K}$ of water with $6 \%$ mass loss. The second mass loss of modified chitosan occurred at $569 \mathrm{~K}$, which resulted in the degradation of biopolymer with a mass loss of $58 \%$, as indicated in Figure 5. The pristine chitosan was found to be more stable than the chemically modified chitosan with a slightly higher mass loss [23].

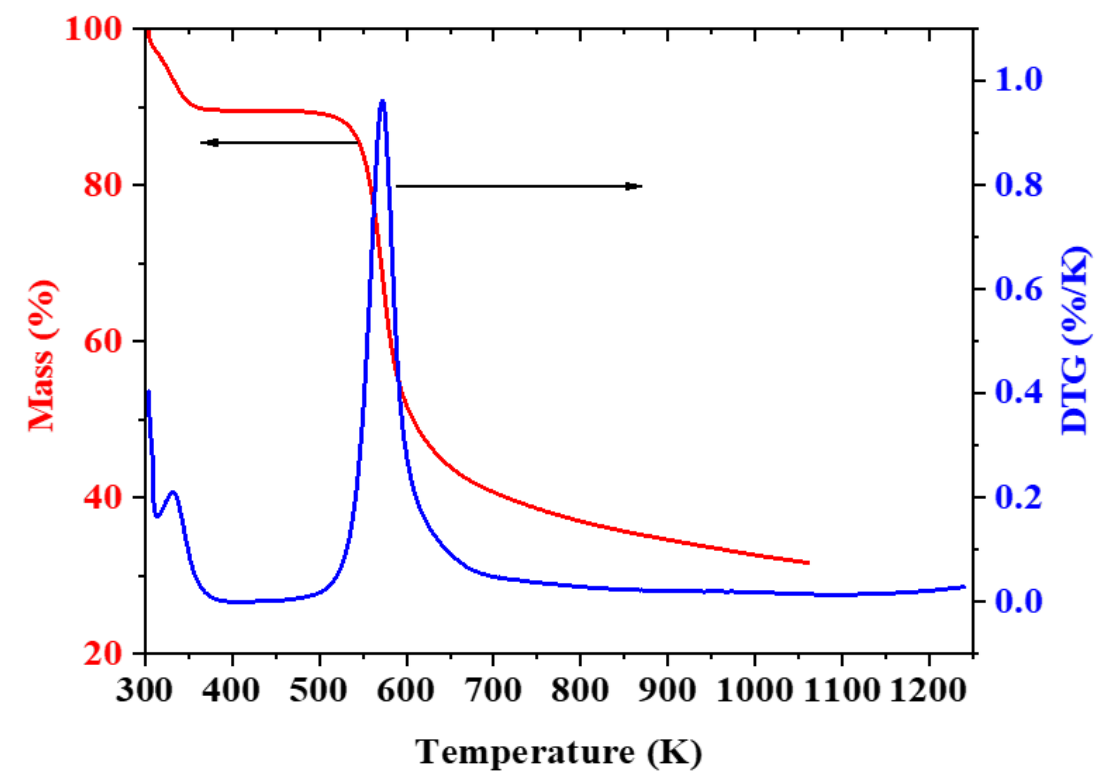

Figure 4. Thermal behavior of pristine $\mathrm{CH}$ in terms of DTG and mass loss profile. 


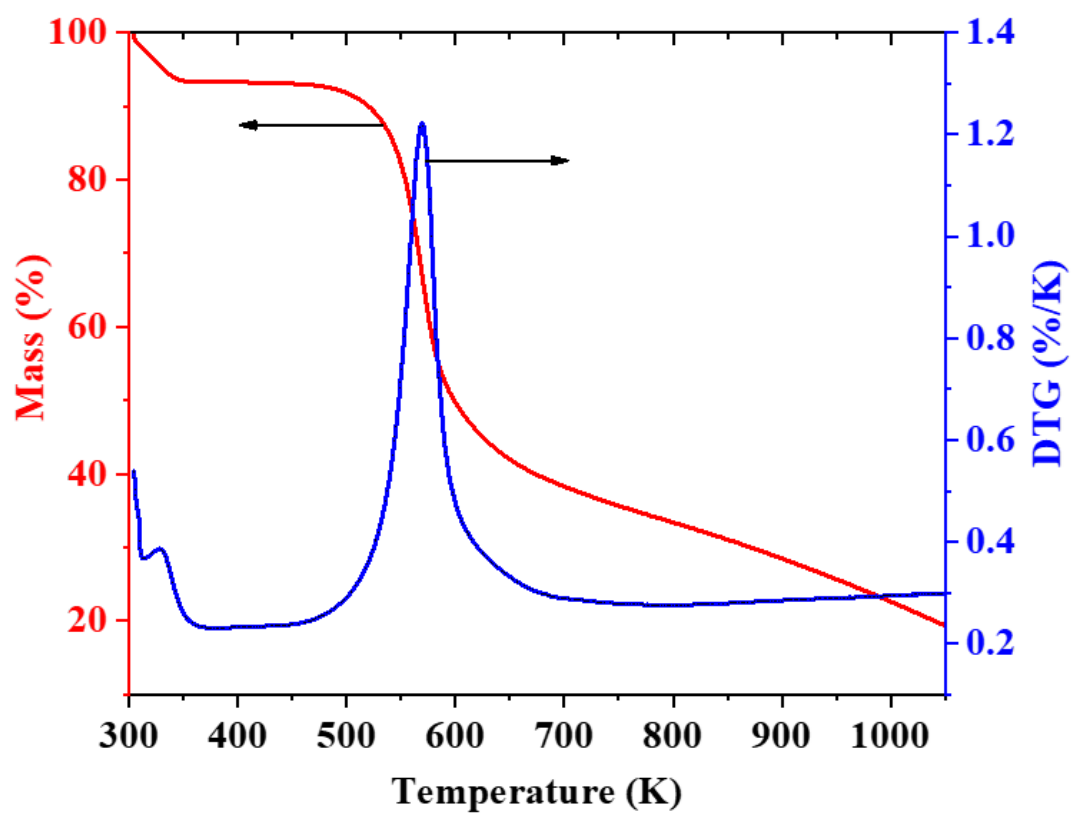

Figure 5. Thermal behavior of chemically modified $\mathrm{CH}$-based final product, i.e., $\mathrm{CH}$-ANP in terms of DTG and mass loss profile.

\subsection{X-ray Diffraction}

The crystallinity of the pristine and chemically modified chitosan (CH-ANP) was determined using X-ray diffraction analysis. Pristine chitosan showed poor crystallinity, as demonstrated in the diffraction pattern in Figure 6. At $2 \theta=9^{\circ}$ and $2 \theta=18^{\circ}$, both the characteristic broad peaks were observed for $\mathrm{CH}$. The diffraction pattern of modified chitosan (CH-ANP) showed slightly different behavior as compared to pristine chitosan. The first peak shifted to a lower value and appeared at $2 \theta=8^{\circ}$, while the second peak appeared at a higher value of $2 \theta=20^{\circ}$. The chemically modified chitosan also displayed low crystallinity due to the insertion of a new molecule into the chitosan pendant chain. This result was also in accordance with those obtained from NMR spectroscopy that mark the precursor chitosan chemical alteration.

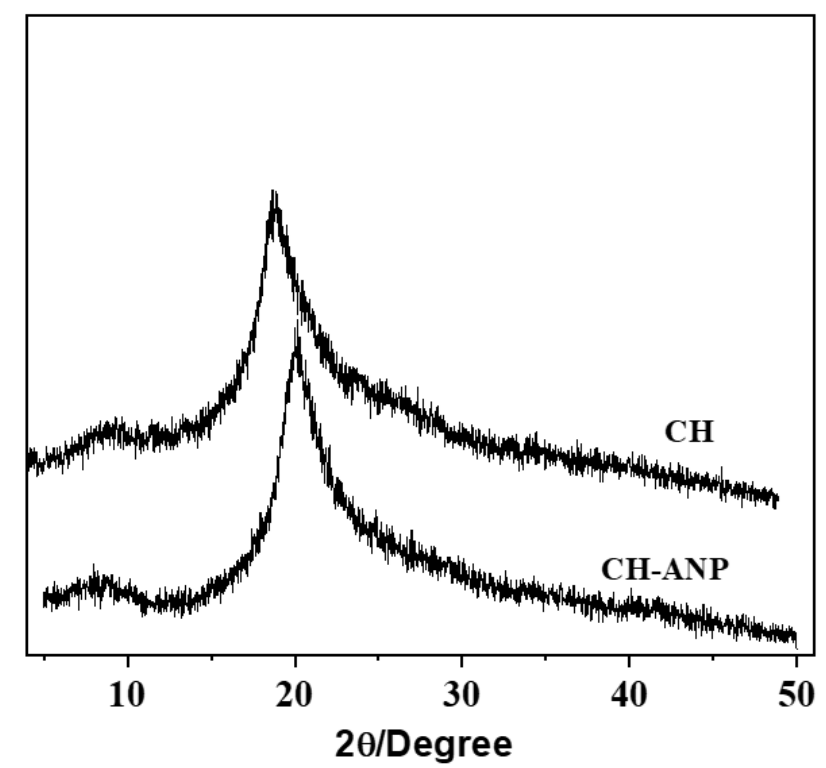

Figure 6. The typical $\mathrm{X}$-ray diffractogram patterns of pristine $\mathrm{CH}$ and the chemically modified $\mathrm{CH}$-based final product, i.e., $\mathrm{CH}-\mathrm{ANP}$. 


\subsection{Sorption Study}

The sorption potential of chemically modified $\mathrm{CH}-\mathrm{ANP}$ was tested against copper, lead, and cadmium in an aqueous environment. The cations sorption occurred on the surface of sorbent when coming in contact with cation solution and the cations partitioned between the sorbent/solution interface. The amount of cations on the sorbent increased with time until a dynamic equilibrium was established; this phenomenon is mostly determined from sorption isotherm. In this study, both linear and nonlinear models for Langmuir, Freundlich, and Temkin isotherms were deployed, and the results obtained are summarized in Table 2 [35]. The results showed that the chemically modified chitosan (CH-ANP) has a higher sorption capacity for copper, lead, and cadmium as compared to the pristine chitosan. The isotherms revealed that the sorption of cations on the surface of sorbent increased with time until surface saturation. The $\mathrm{CH}$-ANP demonstrated higher sorption capacity for copper $\left(2.82 \mathrm{mmol} \mathrm{g}^{-1}\right)$ than cadmium $\left(1.96 \mathrm{mmol} \mathrm{g}^{-1}\right)$ and lead $\left(1.60 \mathrm{mmol} \mathrm{g}^{-1}\right)$ based on Langmuir sorption isotherm type 1, which shows its higher selectivity for copper as compared to the other metals, as shown in Table 3 [36]. The CH-ANP contains nitrogen, which acts as a borderline basic center with relatively high electronegativity, and polarizability favors linkage with the borderline copper atom in contrast to the soft metals lead and cadmium [37]. The raw chitosan exhibited lower sorption capacity for the copper $\left(1.40 \mathrm{mmol} \mathrm{g}^{-1}\right)$ than cadmium $\left(1.35 \mathrm{mmol} \mathrm{g}^{-1}\right)$ and lead $\left(1.19 \mathrm{mmol} \mathrm{g}^{-1}\right)$ in comparison with the chemically modified materials.

Table 2. Sorption isotherm model, the linear and nonlinear representations and respective plot graphical forms.

\begin{tabular}{|c|c|c|c|}
\hline Isotherm & Nonlinear Form & Linear Form & Plot \\
\hline Langmuir type 1 & $N f=\frac{N s b C s}{1+b C s}$ & $\frac{C_{s}}{N f}=\frac{C_{s}}{N s}+\frac{1}{N s b}$ & $\frac{C s}{N f}$ vs Cs \\
\hline Langmuir type 2 & & $\frac{1}{N f}=\left[\frac{1}{N s b}\right] \frac{1}{C s}+\frac{1}{N s}$ & $\frac{1}{N f} v s \frac{1}{C s}$ \\
\hline Langmuir type 3 & & $N f=N s-\left[\frac{1}{b}\right]+\frac{N f}{C s}$ & $N f$ vs $\frac{N f}{C s}$ \\
\hline Langmuir type 4 & & $\frac{N f}{C s}=b N s-b N f$ & $\frac{N f}{C s} v s N f$ \\
\hline Freundlich & $N f=K f C s^{\frac{1}{n}}$ & $\log N f-\log K f+\frac{1}{n} \log C s$ & $\log C s$ vs $\log N f$ \\
\hline Temkin & $N f=\ln \left(K_{T} C s\right)^{\frac{1}{n_{T}}}$ & $N f=n_{T} \ln K_{T}+n_{T} \ln C s$ & $N f=n_{T} \ln K_{T}+n_{T} \ln C$ \\
\hline Standard error & $S E=\sqrt{\frac{1}{m-P}} \sum_{i=1}^{m}\left(N_{f \exp i}-N_{f c a l i}\right)^{2}$ & & \\
\hline Chi-square & $x^{2}=\sum_{i=1} \frac{\left(N_{f \exp i}-N_{f c a l i}\right)^{2}}{N_{f c a l i}}$ & & \\
\hline
\end{tabular}

The quantity of cations sorbed and the remaining supernatant at equilibrium were determined from an isotherm. It also gives information about the interaction between the sorbent and sorbate molecules. The four different Langmuir isotherms types in both linear and nonlinear regression analyses were performed along with experimental data with Freundlich and Temkin models to obtain the best results. It is seen that the anticipated values of constant and the values of correlation coefficients for every one of the four linear forms of Langmuir isotherms are very contrasting, as shown in Table 3. The correlation coefficient value acquired from Langmuir isotherm type 1 was more precise than those of the other linear equations. The obtained correlation coefficient values displayed best fits with the Langmuir type 1 equation to the exploratory information in correlation with direct types of the Langmuir isotherm, as shown in Table 3. Standard Error (SE), chi-square, and $\chi^{2}$ values were extremely little for the Langmuir model type 1, as compared to other tested conditions. 
Table 3. Isotherm results of tested divalent metal ions for their interaction with the chemically modified CH-ANP material. Four different linear types (type I to type IV) of Langmuir were employed under standard conditions. (Abbreviations: $\mathrm{N} f$-number of sorbed moles $\left(\mathrm{mmol} \mathrm{g}^{-1}\right), \mathrm{Ns}\left(\mathrm{mmol} \mathrm{g}^{-1}\right)$, and b ( $\left.\mathrm{g} \mathrm{mmol}^{-1}\right)$-Langmuir parameters, r-correlation coefficients, and SE-standard errors).

\begin{tabular}{|c|c|c|c|c|c|c|}
\hline Material & Isotherm & Constant & Type I & Type II & Type III & Type IV \\
\hline \multirow{18}{*}{ CH-ANP } & \multirow{6}{*}{$\mathrm{Cu}^{2+}$} & $\mathrm{N} f$ & 2.82 & 2.82 & 2.82 & 2.82 \\
\hline & & Ns & $2.94 \pm 0.01$ & $2.93 \pm 0.01$ & $2.95 \pm 0.02$ & $2.95 \pm 0.14$ \\
\hline & & $\mathrm{b}$ & $2.63 \pm 0.01$ & $2.62 \pm 0.01$ & $2.59 \pm 0.01$ & $2.57 \pm 0.06$ \\
\hline & & $\mathrm{R}^{2}$ & 0.999 & 0.996 & 0.993 & 0.993 \\
\hline & & SE & 0.034 & 0.034 & 0.031 & 0.031 \\
\hline & & $x^{2}$ & 0.007 & 0.007 & 0.006 & 0.006 \\
\hline & \multirow{6}{*}{$\mathrm{Pb}^{2+}$} & $\mathrm{N} f$ & 1.60 & 1.60 & 1.60 & 1.60 \\
\hline & & Ns & $1.85 \pm 0.03$ & $1.89 \pm 0.01$ & $1.88 \pm 0.01$ & $1.88 \pm 0.01$ \\
\hline & & $\mathrm{b}$ & $0.61 \pm 0.01$ & $0.57 \pm 0.01$ & $0.58 \pm 0.05$ & $0.58 \pm 0.08$ \\
\hline & & $\mathrm{R}^{2}$ & 0.998 & 0.998 & 0.995 & 0.995 \\
\hline & & SE & 0.016 & 0.016 & 0.016 & 0.016 \\
\hline & & $x^{2}$ & 0.002 & 0.001 & 0.001 & 0.001 \\
\hline & \multirow{6}{*}{$\mathrm{Cd}^{2+}$} & $\mathrm{N} f$ & 1.96 & 1.96 & 1.96 & 1.96 \\
\hline & & Ns & $2.48 \pm 0.03$ & $2.51 \pm 0.01$ & $2.51 \pm 0.02$ & $2.52 \pm 0.01$ \\
\hline & & $\mathrm{b}$ & $0.45 \pm 0.01$ & $0.43 \pm 0.01$ & $0.43 \pm 0.01$ & $0.43 \pm 0.01$ \\
\hline & & $R^{2}$ & 0.998 & 0.999 & 0.993 & 0.993 \\
\hline & & SE & 0.025 & 0.025 & 0.025 & 0.026 \\
\hline & & $x^{2}$ & 0.0026 & 0.003 & 0.003 & 0.003 \\
\hline
\end{tabular}

The error capacities for the Freundlich isotherms indicated higher qualities than the Langmuir isotherm type 1 , as can be seen in the information recorded in Table 4 for artificially altered chitosan. The Temkin sorption isotherm model (direct and nonlinear), as shown in Table 2, was additionally applied to assess the sorption possibilities of the sorbent. Its capability is communicated by the values that appear in Table 2 for copper, lead, and cadmium, showing a lower biopolymer-metal connection for the lead. If there should be an occurrence of a nonlinear model, these isotherms demonstrated a lower relationship coefficient when contrasted with the straight model for altered items, as shown in Table 5. The chi-square $\left(\chi^{2}\right)$ test was used to confirm the proficiency and adjustment of the models, as reported in earlier studies [38]. The dissemination of error and chi-square test esteems were lower on the off chance that Langmuir isotherm type 1 fit the trial information better. The error elements of the Freundlich and Temkin models likewise were higher than that of the Langmuir model, demonstrating its lowest fit to the outcomes. The amount of cations sorbed has been compared with the pristine chitosan. The amount that the cations were sorbed by the modified chitosan has also been compared with already synthesized material available in the literature, as shown in Table 6. However, it is very difficult to compare our results with the literature due to the differences in the chitosan source as well as differences in the degree of deacetylation and the molecular weight of the polymeric chain. This is because the extent of sorption depends on its source, its degree of deacetylation, molecular weight, the nature of the cations, and the $\mathrm{pH}$ of the solution [39]. 
Table 4. Isotherm results of tested divalent metal ions for their interaction with the chemically modified $\mathrm{CH}-\mathrm{ANP}$ material. The results are based on a linear model of Freundlich and Temkin. (Abbreviations: $\mathrm{K}_{f}\left(\mathrm{mmol} \mathrm{g}^{-1}\right)$ and $\mathrm{n}$-Freundlich parameters, $\mathrm{K}_{\mathrm{T}}\left(\mathrm{mmol} \mathrm{dm}^{-3}\right)$, and $\mathrm{b}\left(\mathrm{kJ} \mathrm{mol}^{-1}\right)$-Temkin parameters, $\mathrm{r}$-correlation coefficients, and SE-standard errors).

\begin{tabular}{ccccc}
\hline Isotherm & Constant & $\mathbf{C u}$ (II) & $\mathbf{P b}$ (II) & $\mathbf{C d}$ (II) \\
\hline Freundlich & $\mathrm{K}_{f}$ & $1.74 \pm 0.01$ & $0.71 \pm 0.02$ & $0.80 \pm 0.02$ \\
& $\mathrm{n}$ & $3.37 \pm 0.02$ & $1.72 \pm 0.03$ & $2.46 \pm 0.03$ \\
& $\mathrm{R}^{2}$ & 0.916 & 0.985 & 0.951 \\
$\mathrm{SE}$ & 0.59 & 0.03 & 0.35 \\
& $\chi^{2}$ & 5.12 & 0.30 & 0.60 \\
\hline Temkin & $\mathrm{K}_{\mathrm{T}}$ & $43.56 \pm 0.02$ & $6.24 \pm 0.01$ & $4.08 \pm 0.02$ \\
& $\mathrm{~b}$ & $0.879 \pm 0.01$ & $2.46 \pm 0.03$ & $1.39 \pm 0.01$ \\
& $\mathrm{R}^{2}$ & 0.970 & 0.970 & 0.991 \\
& $\mathrm{SE}$ & 0.08 & 0.05 & 0.04 \\
& $\chi^{2}$ & 0.603 & 0.010 & 0.010 \\
\hline
\end{tabular}

Table 5. Isotherm results of tested divalent metal ions for their interaction with the chemically modified $\mathrm{CH}-\mathrm{ANP}$ material. The results are based on nonlinear Langmuir, Freundlich, and Temkin models. (Abbreviations: $\mathrm{N} f$-number of sorbed moles $\left(\mathrm{mmol} \mathrm{g}^{-1}\right)$, $\mathrm{Ns}\left(\mathrm{mmol} \mathrm{g}^{-1}\right)$, and b $\left(\mathrm{g} \mathrm{mmol}^{-1}\right)$-Langmuir parameters, $\mathrm{K}_{f}\left(\mathrm{mmol} \mathrm{g}^{-1}\right)$ and $\mathrm{n}$-Freundlich parameters, $\mathrm{K}_{\mathrm{T}}\left(\mathrm{mmol} \mathrm{dm}^{-3}\right)$, and b $\left(\mathrm{kJ} \mathrm{mol}^{-1}\right)$-Temkin parameters, $\mathrm{r}$ - correlation coefficients, and SE—standard errors).

\begin{tabular}{ccccc}
\hline Isotherm & Constant & $\mathbf{C u}(\mathbf{I I})$ & $\mathbf{P b}$ (II) & $\mathbf{C d}$ (II) \\
\hline \multirow{3}{*}{ Langmuir } & $\mathrm{N} f$ & 2.82 & - & - \\
& $\mathrm{Ns}$ & $2.96 \pm 0.01$ & $1.87 \pm 0.01$ & $3.50 \pm 0.03$ \\
& $\mathrm{~b}$ & $2.53 \pm 0.07$ & $0.59 \pm 0.01$ & $0.44 \pm 0.01$ \\
& $\mathrm{R}^{2}$ & 0.998 & 0.997 & 0.997 \\
Freundlich & $\chi^{2}$ & 0.001 & 0.003 & 0.0006 \\
& $\mathrm{~K}_{f}$ & $1.84 \pm 0.08$ & $0.81 \pm 0.04$ & $0.88 \pm 0.04$ \\
& $\mathrm{n}$ & $4.12 \pm 0.51$ & $3.28 \pm 0.32$ & $2.56 \pm 0.21$ \\
& $\mathrm{R}^{2}$ & 0.904 & 0.945 & 0,957 \\
Temkin & $\chi^{2}$ & 0.062 & 0.007 & 0.01 \\
& $\mathrm{~K}_{\mathrm{T}}$ & $42.32 \pm 11.40$ & $6.76 \pm 1.20$ & $4.08 \pm 0.3$ \\
& $\mathrm{~b}$ & $1.94 \pm 0.11$ & $2.57 \pm 0.31$ & $1.39 \pm 0.05$ \\
& $\mathrm{R}^{2}$ & 0.964 & 0.980 & 0.992 \\
& $\chi^{2}$ & 0.023 & 0.002 & 0.001 \\
\hline
\end{tabular}

Table 6. Comparison of chemically modified chitosan (CH-ANP) with the literature for divalent cations sorption $\left(\mathrm{mmol} \mathrm{g}^{-1}\right)$ from aqueous solution.

\begin{tabular}{|c|c|c|c|c|}
\hline Sorbent & $\mathrm{Cu}(\mathrm{II})\left(\mathrm{mmol} \mathrm{g}^{-1}\right)$ & $\mathrm{Pb}$ (II) (mmol g-1) & $\mathrm{Cd}$ (II) $\left(\mathrm{mmol} \mathrm{g}^{-1}\right)$ & References \\
\hline CS-ag-CM & & 0.88 & 1.49 & [40] \\
\hline Chitosan-Vanillin-Schiff base & & 0.11 & & \\
\hline Chitosan-O-Vanillin Schiff base & & 0.319 & & [41] \\
\hline Chitosan-Schiff base & 1.74 & & & [42] \\
\hline PLLA/CH & 1.75 & & & [43] \\
\hline $\begin{array}{l}\text { grafted crosslinked chitosan } \\
\text { beads (G/ECH-CS) }\end{array}$ & 0.47 & 0.19 & 0.14 & [44] \\
\hline Modified chitosan beads & 2.21 & & 1.58 & [28] \\
\hline $\begin{array}{l}\text { Glutaric acid modified } \mathrm{Pb}(\mathrm{II}) \\
\text { imprinted chitosan-based } \\
\text { composite membrane }\end{array}$ & & 0.36 & & [45] \\
\hline bentonite-chitosan composite & & 0.39 & 0.84 & [46] \\
\hline CH-ANP & 2.82 & 1.60 & 1.96 & Present Work \\
\hline
\end{tabular}




\section{Conclusions}

The incorporation of nitrogen basic centers in chitosan by chemical modification with glycidyl methacrylate and 1,4-bis (3-aminopropyl) piperazine was carried out and confirmed by NMR spectroscopy in solid-state, elemental analysis, infrared spectroscopy, XRD and thermal analysis. The engineered chitosan derivative exhibited superior sorption capacity for selected cations than the pristine chitosan. The nonlinear and linear relapse examinations were utilized for every one of the three models: the Freundlich, Langmuir, and Temkin. In agreement with linear and nonlinear relapse, the Langmuir model type 1 gave the minimal estimations of the error compared with the Temkin and Freundlich models, and fitted well to the test information in comparison to the other two models. The four diverse types of the Langmuir isotherm yield various estimations of error and parameters, which is expected to change the nonlinear equations into a linear equation, and thus influence the appropriation of errors. In the event of a nonlinear technique, there were no issues related to changing the nonlinear equation to the linear form; every one of the three models gave lower estimations of errors when utilizing the nonlinear strategy.

Author Contributions: Conceptualization, N.A.; A.K.; Experimental and data collection, S.M.; S.B.; Data analysis and validation, A.K.; Writing-Original Draft Preparation, N.A.; A.K.; Writing and Editing, M.B.; H.M.N.I.; and APC Funding Acquisition, H.M.N.I.

Funding: This research was funded by The acadmey of sciences for developing world (TWAS) and The Brazilian National Council for Scientific and Technological Development (CNPq) fellowship to AK. The APC was funded by MDPI, St. Alban-Anlage 66, 4052 Basel, Switzerland.

Acknowledgments: All listed authors are grateful to their representative departments and universities for the financial support and analytical services used in this study.

Conflicts of Interest: The authors report no conflict of interest.

\section{References}

1. Al-Senani, G.M.; Al-Fawzan, F.F. Adsorption study of heavy metal ions from aqueous solution by nanoparticle of wild herbs. Egypt. J. Aquat. Res. 2018, 44, 187-194. [CrossRef]

2. Rahman, S.; Kathiresan, V.; Sathasivam, K.V. Heavy Metal Adsorption onto Kappaphycus sp. From Aqueous Solutions: The Use of Error Functions for Validation of Isotherm and Kinetics Models. BioMed Res. Int. 2015, 2015, 126298. [CrossRef] [PubMed]

3. Wani, A.L.; Anjum, A.R.A.; Usmani, J.A. Lead toxicity: A review. Interdiscip. Toxicol. 2015, 8, 55-64. [CrossRef] [PubMed]

4. Assi, M.A.; Hezmee, M.N.; Haron, A.W.; Sabri, M.Y.; Rajion, M.A. The detrimental effects of lead on human and animal health. Vet. World 2016, 9, 660-671. [CrossRef] [PubMed]

5. Mason, L.H.; Harp, J.P.; Han, D.Y. Pb Neurotoxicity: Neuropsychological Effects of Lead Toxicity. BioMed Res. Int. 2015, 2014, 840547. [CrossRef]

6. Bernhoft, R.A. Cadmium toxicity and treatment. Sci. World J. 2013, 2013, 394652. [CrossRef]

7. Rahimzadeh, M.R.; Rahimzadeh, M.R.; Kazemi, S.; Moghadamnia, A.A. Cadmium toxicity and treatment: An update. Casp. J. Intern. Med. 2017, 8, 135-145.

8. Ashish, B.; Neeti, K.; Himanshu, K. Copper Toxicity: A Comprehensive Study. Res. J. Recent Sci. 2013, 2, 58-67.

9. Bilal, M.; Rasheed, T.; Sosa-Hernández, J.E.; Raza, A.; Nabeel, F.; Iqbal, H.M.N. Biosorption: An interplay between marine algae and potentially toxic elements-A review. Mar. Drugs 2018, 16, 65. [CrossRef]

10. Rasheed, T.; Li, C.; Bilal, M.; Yu, C.; Iqbal, H.M.N. Potentially toxic elements and environmentally-related pollutants recognition using colorimetric and ratiometric fluorescent probes. Sci. Total Environ. 2018, 640, 174-193. [CrossRef]

11. Rasheed, T.; Bilal, M.; Nabeel, F.; Iqbal, H.M.N.; Li, C.; Zhou, Y. Fluorescent sensor based models for the detection of environmentally-related toxic heavy metals. Sci. Total Environ. 2018, 615, 476-485. [CrossRef] [PubMed]

12. Meng, L.; Guo, L.; Guo, Z. Separation of metals from metal-rich particles of crushed waste printed circuit boards by low-pressure filtration. Waste Manag. 2019, 84, 227-234. [CrossRef] [PubMed] 
13. Ngcephe, A.M.; Sinha, M.K.; Purcell, W. Solvent extraction and separation of palladium from platinum group elements: Synthesis and characterization of 2-mercaptopyridine N-oxide-palladium (II) complex. J. Mol. Struct. 2020, 1199, 127009. [CrossRef]

14. Khan-mohammadi, H.; Bayati, B.; Rahbar-Shahrouzi, J.; Babaluo, A.; Ghorbani, A. Molecular simulation of the ion exchange behavior of $\mathrm{Cu}^{2+}, \mathrm{Cd}^{2+}$ and $\mathrm{Pb}^{2+}$ ions on different zeolites exchanged with sodium. J. Environ. Chem. Eng. 2019, 7, 103040. [CrossRef]

15. Vaneeckhaute, C.; Darveau, O.; Meers, E. The fate of micronutrients and heavy metals in digestate processing using vibrating reversed osmosis as resource recovery technology. Sep. Purif. Technol. 2019, 223, 81-87. [CrossRef]

16. Itam, Z.; Beddu, S.; Mohammad, D.; Kamal, N.L.M.; Hamid, Z.A.A. Extraction of Metal Oxides from Coal Bottom Ash by Carbon Reduction and Chemical Leaching. Mater. Today Proc. 2019, 17, 727-735. [CrossRef]

17. Vajedi, F.S.; Dehghani, H. The characterization of $\mathrm{TiO}_{2}$-reduced graphene oxide nanocomposites and their performance in electrochemical determination for removing heavy metals ions of cadmium(II), lead(II) and copper(II). Mater. Sci. Eng. B 2019, 243, 189-198. [CrossRef]

18. Hussain, S.; Ullah, Z.; Gul, S.; Khattak, R.; Kazmi, N.; Rehman, F.; Khan, S.; Ahmad, K.; Imad, M.; Khan, A. Adsorption Characteristics of Magnesium-Modified Bentonite Clay with Respect to Acid Blue 129 in Aqueous Media. Pol. J. Environ. Stud. 2016, 25, 1947-1953. [CrossRef]

19. Alhokbany, N.; Naushad, T.A.M.; Alshehri, S.M. Feasibility of toxic metal removal from aqueous medium using Schiff-base based highly porous nanocomposite: Adsorption characteristics and post characterization. J. Mol. Liq. 2019, 294, 111598. [CrossRef]

20. Gupta, R.; Gupta, S.K.; Pathak, D.D. Selective adsorption of toxic heavy metal ions using guanine-functionalized mesoporous silica [SBA-16-g] from aqueous solution. Microporous Mesoporous Mater. 2019, 288, 109577. [CrossRef]

21. Khan, A.; Wahid, F.; Ali, N.; Badshah, S.; Airoldi, C. Single-step modification of chitosan for toxic cations remediation from aqueous solution. Desalin. Water Treat. 2015, 56, 1099-1109. [CrossRef]

22. Khan, A.; Badshah, S.; Airoldi, C. Biosorption of some toxic metal ions by chitosan modified with glycidyl methacrylate and diethylenetriamine. Chem. Eng. J. 2011, 171, 159-166. [CrossRef]

23. Khan, A.; Badshah, S.; Airoldi, C. Dithiocarbamated chitosan as a potent biopolymer for toxic cation remediation. Colloids Surf. B Biointerfaces 2011, 87, 88-95. [CrossRef] [PubMed]

24. Khan, A.; Shah, S.J.; Mehmood, K.; Ali, N.; Khan, H. Synthesis of potent chitosan beads a suitable alternative for textile dye reduction in sunlight. J. Mater. Sci. Mater. Elect. 2018, 30, 406-414. [CrossRef]

25. Cinar, S.; Kaynar, U.H.; Aydemir, T.; Kaynar, S.C.; Mehmet Ayvaciklı, M. An efficient removal of RB5 from aqueous solution by adsorption onto nano-ZnO/Chitosan composite beads. Int. J. Biol. Macromol. 2017, 96, 459-465. [CrossRef] [PubMed]

26. Jawad, A.H.; Norrahma, S.S.A.; Hameed, B.H.; Ismail, K. Chitosan-glyoxal film as a superior adsorbent for two structurally different reactive and acid dyes: Adsorption and mechanism study. Int. J. Biol. Macromol. 2019, 135, 569-581. [CrossRef]

27. Bilal, M.; Iqbal, H.M.; Hu, H.; Wang, W.; Zhang, X. Enhanced bio-catalytic performance and dye degradation potential of chitosan-encapsulated horseradish peroxidase in a packed bed reactor system. Sci. Total Environ. 2017, 575, 1352-1360. [CrossRef]

28. Sutirman, Z.A.; Sanagi, M.M.; Karim, K.J.A.; Ibrahim, W.A.W.; Jume, B.H. Equilibrium, kinetic and mechanism studies of $\mathrm{Cu}$ (II) and Cd (II) ions adsorption by modified chitosan beads. Int. J. Biol. Macromol. 2018, 116, 255-263. [CrossRef]

29. Salih, S.S.; Ghosh, T.K. Adsorption of Zn(II) ions by chitosan coated diatomaceous earth. Int. J. Biol. Macromol. 2018, 106, 602-610. [CrossRef]

30. Zhai, L.; Bai, Z.; Zhu, Y.; Wang, B.; Luo, W. Fabrication of chitosan microspheres for efficient adsorption of methyl orange. Chin. J. Chem. Eng. 2018, 26, 657-666. [CrossRef]

31. Frantz, T.S.; Silveira, N., Jr.; Quadro, M.S.; Andreazza, R.; Barcelos, A.A.; Cadaval, T.R.S., Jr.; Pinto, L.A.A. $\mathrm{Cu}(\mathrm{II})$ adsorption from copper mine water by chitosan films and the matrix effects. Environ. Sci. Pollut. Res. 2017, 24, 5908-5917. [CrossRef]

32. Hui, M.; Shengyan, P.; Yaqi, H.; Rongxin, Z.; Anatoly, Z.; Wei, C. A highly efficient magnetic chitosan "fluid" adsorbent with a high capacity \& fast adsorption kinetics for dyeing wastewater purification. Chem. Eng. J. 2018, 345, 556-565. 
33. Chen, H.; Wageh, S.; Al-Ghamdi, A.A.; Wang, H.; Yu, J.; Jiang, C. Hierarchical C/NiO-ZnO nanocomposite fibers with enhanced adsorption capacity for Congo red. J. Colloid Interface Sci. 2019, 537, 736-745. [CrossRef]

34. Sousa, K.S.; Silva Filho, E.C.; Airoldi, C. Ethylenesulfide as a useful agent for incorporation into the biopolymer chitosan in a solvent-free reaction for use in cation removal. Carbohydr. Res. 2009, 344, 1716-1723. [CrossRef]

35. Khan, A.; Badshah, S.; Airoldi, C. Single-step modification of chitosan for toxic cations remediation from aqueous solution. Polym. Bull. 2015, 72, 353-370. [CrossRef]

36. Tahira, I.; Aslam, Z.; Abbas, A.; Monim-ul-Mehboob, M.; Ali, S.; Asghar, A. Adsorptive removal of acidic dye onto grafted chitosan: A plausible grafting and adsorption mechanism. Int. J. Biol. Macromol. 2019, 136, 1209-1218. [CrossRef]

37. Lopes, E.C.N.; Sousa, K.S.; Airoldi, C. Chitosan-cyanuric chloride intermediary as a source to incorporate molecules-Thermodynamic data of copper/biopolymer interactions. Thermochim. Acta 2008, 483, 21-28. [CrossRef]

38. Azari, A.; Noorisepehr, M.; Dehghanifard, E.; Karimyan, K.; Hashemi, S.Y.; Kalhori, E.M.; Norouzi, R.; Agarwal, S.; Gupta, V.K. Experimental design, modeling and mechanism of cationic dyes biosorption on to magnetic chitosan-glutaraldehyde composite. Int. J. Biol. Macromol. 2019, 131, 633-645. [CrossRef]

39. Machado, M.O.; Lopes, E.C.N.; Sousa, K.S.; Airoldi, C. The effectiveness of the protected amino group on crosslinked chitosans for copperremoval and the thermodynamics of interaction at the solid/liquid interface. Carbohydr. Polym. 2009, 77, 760-766. [CrossRef]

40. Manzoor, K.; Ahmad, M.; Ahmad, S.; Ikram, S. Removal of $\mathrm{Pb}(\mathrm{II})$ and $\mathrm{Cd}(\mathrm{II})$ from wastewater using arginine cross-linked chitosan-carboxymethyl cellulose beads as green adsorbent. RSC Adv. 2019, 9, 7890-7902. [CrossRef]

41. Alakhras, F.; Al-Shahrani, H.; Al-Abbad, E.; Al-Rimawi, F.; Ouerfelli, N. Removal of Pb(II) Metal Ions from Aqueous Solutions Using Chitosan-Vanillin Derivatives of Chelating Polymers. Pol. J. Environ. Stud. 2019, 28, 1523-1534. [CrossRef]

42. Anush, S.M.; Chandan, H.R.; Vishalakshi, B. Synthesis and metal ion adsorption characteristics of graphene oxide incorporated chitosan Schiff base. Int. J. Biol. Macromol. 2019, 126, 908-916. [CrossRef]

43. Zia, Q.; Tabassum, M.; Lu, Z.; Khawar, M.T.; Song, J.; Gong, H.; Meng, J.; Li, Z.; Li, J. Porous poly (L-lactic acid)/chitosan nanofibres for copper ion adsorption. Carbohydr. Polym. 2020, 227, 115343. [CrossRef]

44. Igberase, E.; Ofomaja, A.; Osifo, P.O. Enhanced heavy metal ions adsorption by 4-aminobenzoic acid grafted on chitosan/epichlorohydrin composite: Kinetics, isotherms, thermodynamics and desorption studies. Int. J. Biol. Macromol. 2019, 123, 664-676. [CrossRef] [PubMed]

45. Lv, X.; Liu, Y.; Zhang, J.; Zhao, M.; Zhu, K. Study on the adsorption behavior of glutaric acid modified Pb(II) imprinted chitosan-based composite membrane to $\mathrm{Pb}(\mathrm{II})$ in aqueous Solution. Mater. Lett. 2019, 251, 172-175. [CrossRef]

46. Sellaoui, L.; Soetaredjo, F.E.; Ismadji, S.; Bonilla-Petriciolet, A.; Belver, C.; Bedia, J.; Lamine, A.B.; Erto, A. Insights on the statistical physics modeling of the adsorption of $\mathrm{Cd}^{2+}$ and $\mathrm{Pb}^{2+}$ ions on bentonite-chitosan composite in single and binary systems. Chem. Eng. J. 2018, 354, 569-576. [CrossRef]

(C) 2019 by the authors. Licensee MDPI, Basel, Switzerland. This article is an open access article distributed under the terms and conditions of the Creative Commons Attribution (CC BY) license (http://creativecommons.org/licenses/by/4.0/). 